\title{
Remarks on the use of Pearson's and Spearman's correlation coefficients in assessing relationships in ophthalmic data
}

Author:
Ali M. Alsaqr ${ }^{1}$
Affiliation:
'Department of Optometry,
College of Applied Medical
Sciences, King Saud
University, Riyadh, Saudi
Arabia
Corresponding author:
Ali Alsaqr,
aalsaqr@ksu.edu.sa
Dates:
Received: 06 Sept. 2020
Accepted: 10 Feb. 2021
Published: 21 Apr. 2021
code with your
How to cite this article:
Alsaqr AM. Remarks on the
use of Pearson's and
Spearman's correlation
to read online.
coefficients in assessing
relationships in ophthalmic
data. Afr Vision Eye Health.
2021;80(1), a612. https://doi.
org/10.4102/aveh.v80i1.612
Copyright:
C 2021. The Author(s).
Licensee: AOSIS. This work
is licensed under the
Creative Commons
Attribution License.

Background: A correlation coefficient is a measure of a relationship between any two quantitative and categorical variables. The coefficient describes the degree of relationship between two variables. Associated variables change in tandem - a change in one variable, and the second changes in the same or opposite direction. Correlation is a commonly used statistical procedure. Medical studies use this test widely to explore diagnosis, prognosis and predicting normative parameters for reference measurements. This test is not uncommon in the ophthalmic field, and many studies in the literature used this statistical procedure. However, in some studies, the interpretation of this test was incorrect, possibly because of the test being partially misunderstood.

Aim: This study aims to review articles that used those statistic tests to provide an overview of correlation coefficient tests, their indications and interpretations. Correlation analyses and interpretations in ophthalmic data studies are also discussed.

Methods: The preferred reporting items for systematic reviews and meta-analyses guidelines were followed and correlation studies that explored ophthalmic data were searched, investigated and reviewed. This review covered a span over the period published between 1990-2020.

Results: This critical review included 64 papers. The papers were directed to investigate many variables, for example, visual acuity, contrast sensitivity, dry eye, myopia, retina and low vision. Some of those papers found significant results while the others did not report any. Their reporting and interpretation of the correlation coefficient varied widely.

Conclusion: The studies reviewed suggested that there is a need for reporting, in every single study, the normality of the data, $r$-value, $p$-value and the extent of the shared variance between investigated outcomes. Lastly, the clinical implications of those studies findings are recommended to be stated clearly.

Keywords: correlation; Pearson's; Spearman's; statistics; ocular; eye; vision; ophthalmology; optometry.

\section{Background}

Reading a scientific article requires knowledge of statistical analysis and interpretation of research data. The determination of clinical significance and implications of statistical outcomes also requires knowledge of statistical symbols and values, and their interpretation. Specifically, evaluating the relationship between two factors or variables is crucial in the medical field. These analyses can help to improve prognosis or lead to deterioration of ocular conditions. The analyses also highlight the importance of measuring the visual function, assessing a tissue, or recommending using one tool or procedure over others. Correlation analysis also shows how strong and significant is the relationship between the two variables concerned. Correlations can be measured using different indices or coefficients. ${ }^{1}$ The two most popular statistical tests for investigating relationship include Pearson's and Spearman's coefficients. ${ }^{1,2,3,4,5,6}$

Pearson's correlation coefficient is a parametric test, which requires normally distributed continuous variables. ${ }^{3,7,8}$ Non-normally distributed data should be evaluated using correlation coeffcients calculated from the ranks of the data. ${ }^{7,8}$ The test designed for this purpose is Spearman's rho correlation coefficient. ${ }^{1,3,7,9}$ Pearson's tests use linear modelling relationships to describe how well a relationship describes an interaction between variables. ${ }^{2}$ Spearman's coefficient uses a monotonic function to assess relationships with rank variables. ${ }^{2}$ Critical factors affecting the 
choice of a correlation coefficient test include data type, linearity of relationships, presence of outliers and adherence to the parametric assumption. ${ }^{2}$

The correlation coefficient $(r)$ is a statistical measure of the strength of linear relationship between two variables. ${ }^{1}$ The correlation coefficient is bounded between -1 and +1 , inclusive. ${ }^{10}$ The strength of the correlation increases from 0 to 1. A value of zero indicates no correlation; a value of one means a complete correlation (and $100 \%$ of the variance is explained by the relationship). ${ }^{9}$ The sign of the $r$-value indicates a correlation direction, either direct $(+)$ or inverse $(-) .{ }^{10}$ Therefore, an absolute necessity is explicit reporting of strength and direction of $r$ when reporting correlation coeffcients in the literature. The authors reporting relationships usually use terms, such as perfect, strong, good and weak. ${ }^{9}$ Unfortunately, no standard exists amongst the authors in the field. The same value of $r$ is described differently by several researchers in terms of strength. ${ }^{9}$ However, in general, a correlation coefficient $(r)$ of $<0.20$ is often considered 'very weak' or 'negligible'.11 Correlation coefficients $(r)$ of $0.30-0.40$ are often classified as a low or fair or mild relationship, of $0.40-0.70$ as a moderate relationship, of $0.70-0.90$ a strong or high relationship and $>0.90$ as a 'very high' relationship.,12,13,14,15 However, even these suggested cut-off points are still arbitrary and inconsistent, and should be used carefully. For instance, an $r$-value of 0.60 could be interpreted as either 'good' or 'moderate'. A correlation coefficient $(r)$ of 0.39 represents a 'weak' association, whereas 0.40 presents a 'moderate' relationship and the transition is difficult to justify. ${ }^{3}$ Thus, interpreting the clinical significance of an association is perhaps more important than classifying the strength of a relationship.

When interpreting a correlation coefficient $(r)$, investigators should consider the coefficient of determination $\left(r^{2}\right)$ value, in addition to the $r$ - and $p$-values. ${ }^{16}$ This coefficient $\left(r^{2}\right)$ indicates the proportion of variance shared between two variables. $4,15,17,18,19$ For example, if we observed an $r$-value of $0.40,16 \%$ of the variation in one variable is explained by variation in the second variable concerned. ${ }^{10,18}$

Hauke and Tomasz ${ }^{1}$ compared Pearson's and Spearman's coefficients on the same set of data. They concluded that significance in one test might be accompanied by either significance or non-significance in the other, even for large data sets. The two tests have their own specific assumptions, and subsequently, differences exist between the two coefficients; a negative relationship can be identified by one test and a positive coefficient in the other. ${ }^{1}$ It is crucial, therefore, to understand assumptions regarding data underlying each test and to check the normality of data before starting statistical analyses, the suggestion of which is supported by others, such as Rebekic et al. ${ }^{2}$ They also compared Pearson's and Spearman's coefficients on the same set of variables in winter wheat genotypes. Although they found some similarity between the two tests in terms of correlation coefficients strength and significance, they also found some discrepancies between both tests, especially in terms of finding a non-significant outcome in Pearson's test and a significant outcome in Spearman's coefficient test. They concluded that the most crucial factors affecting the choice of an appropriate test include data type, linearity of relationship, presence of outliers and violation of parametric assumptions.

One of the main goals of statistical analysis was to provide an evaluation of confidence regarding the size of an effect of the investigated matter. It is common to express such confidence in terms of 'probabilities' of hypotheses. ${ }^{20}$ Misinterpretation and misuse of statistical tests may involve statistical significance. ${ }^{20}$ For example, a medical journal suggested that denying the null hypothesis via a significance testing procedure is invalid, and therefore, authors are not required to present it in their articles. ${ }^{21}$ Specifically, the statistical analysis classifies results as significant or non-significant based on a $p$ value..$^{22}$ The variable $p$ stands for probability and measures what is the probability that an observed difference between groups is because of chance. ${ }^{23} \mathrm{~A} p$-value close to 0 means that the observed difference is unlikely to be accounted for chance, whereas a $p$-value close to 1 indicates no difference between the groups other than because of mostly chance. ${ }^{23}$ Fisher proposed a 0.05 cut-off point, where $p<0.05$ (5\% significance) considered as a standard level for concluding that there is evidence against the hypothesis tested. ${ }^{24}$ The smaller $p$ value indicates the greater statistical incompatibility of the data with the null hypothesis and vice versa with the greater $p$-value. ${ }^{22}$ Specifically, $p>0.05$ can indicate that no evidence of difference exist, although it does not mean that there is no difference between the groups.22 A value of $p>$ 0.05 can be a result of several factors, including incorrect study design, imprecise measurement, inaccurate statistical analysis or small sample size. ${ }^{22}$ Therefore, $p>0.05$ does not warrant that no difference exist between the groups, but would mean that no difference was observed in this specific observation. ${ }^{22}$ The American Statistical Association released six principles regarding the interpretation and proper use of values and the reporting of $p$-values. ${ }^{25}$ The purpose of this study, therefore, was to review the two popular correlation coeffcients reported in ophthalmic data, summarise the strength of correlation coeffcients and discuss issues on the use of Pearson's and Spearman's correlation coefficients and their interpretation.

\section{Methods and materials}

The preferred reporting items for systematic reviews and meta-analyses (PRISMA) guidelines were followed whilst preparing this review. ${ }^{26}$ The search focused on relevant peerreviewed publications in eye healthcare that used Pearson's and Spearman's tests. The author employed systematic searches for PubMed and Science Direct databases using dates during the period 1990-2020. Databases of publications, such as Google scholar, and manual searches were also used. Several keywords were used in different combinations, including ocular, eye, vision, visual, ophthalmology, optometry, association, correlation, relationship, Pearson's and Spearman's test. The author screened information in 
identified articles to remove any duplicate paper from the review list. Abstracts were screened, and non-relevant manuscripts were excluded. The remaining papers were studied to determine which should be included in the review.

Initially, 1310 papers were identified using the PubMed and Science Direct search. Additional 250 papers were found using other search methods. After duplicate papers were removed, 1120 papers remained. Abstracts were screened initially to ensure that relationships under investigation were assessed with Pearson's and Spearman's tests. In some papers, statistical methods were not stated. Therefore, additional vetting of 300 full-text articles was completed. Finally, 64 papers were included and critically reviewed as they satisfied the inclusion criteria, including the papers published on eye healthcare between 1990 and 2020, which used one of the two targeted statistical tests.

\section{Exploring relationships in ophthalmic data}

Researchers have investigated several factors that could influence visual acuity (VA), contrast sensitivity (CS) and astigmatism. Terry et al. $^{27}$ investigated the relationship between the donor corneal thickness and post-operative vision. They concluded that a significant but weak relationship exists between them but did not control for age (Table 1). Subjects' age ranged from 31 to 90 years, which is a wide range that encompasses many age-related visual and physiological differences. Nejabat et al. ${ }^{28}$ observed a weak relationship between the keratoconus corneal cylinder and RGP-corrected VA (Table 1). This result suggests that patients with advanced keratoconus showed poorer VA with RGP lenses, an expected outcome. A study by Bilen et al. ${ }^{29}$ reported that refraction and several topographic, pachymetric and wavefront indices derived from Galilei's corneal wavefront instrument showed a significant relationship with CS and $\operatorname{logMAR}$ VA, although they did not report the strength of the relationship found (Table 1). ${ }^{29}$ Furthermore, Kamiya et al. found a correlation between the Objective Scatter Index (OSI) and VA, but no association was found with corneal high-order aberration after Descemet's stripping automated endothelial keratoplasty (Table 1).$^{30}$ Finally, Kawamorita et al. reported a relationship between central and peripheral astigmatism (Table 1). ${ }^{31}$

Some researchers were interested in investigating the impact of reduced VA and loss of visual field (VF) on the quality of life (QoL). Specifically, Sawada et al. ${ }^{32}$ explored the relationship between the scores of QoL questionnaire and the loss of VF and VA in open-angle glaucoma patients. They reported a good correlation between the QoL and VF loss in 10 out of 12 subscales (Table 1). They also reported a weaker significant relationship with VA (Table 1). This was because of VA being mostly maintained until the late stages of glaucoma. However, the strength of relationships and coefficients of determination were not fully discussed in this study.

Other studies were directed towards investigating dry eye disease. For example, Herbaut et al. ${ }^{33}$ investigated Ocular Surface Disease Index, measurement of tear film break-up time, the Oxford score, van Bijsterveld score and Schirmer I test related to OSI recorded over $20 \mathrm{~s}$ without blinking. They reported that the OSI significantly correlated with all these parameters (Table 1). However, most correlation coefficients were $<0.3$, indicating that the variation shared between these variables was only in the range of $2 \%-4 \%$, which is consistent with a relatively poor relationship. Accommodation and accommodative convergence were investigated to explore some factors influencing their measurements using both statistical tests of interest in this review. Bruce et al. ${ }^{34}$ found a relationship between the accommodative convergence to accommodation (AC/A) ratio and convergence accommodation to convergence $(\mathrm{CA} / \mathrm{C})$ ratio with age (Table 2). They reported the strength of the relationship in accordance with the suggested interpretation mentioned earlier. They suggested that AC/A ratios increase $0.126 \mathrm{pd} / \mathrm{D}$ per year and CA/C decreases $0.003 \mathrm{D} /$ pd per year. Gwiazda et al. ${ }^{35}$ reported a 'strong' correlation between myopia and blur-driven accommodation (Table 1). The authors also suggested that increasing accommodative functioning might prove effective in slowing down the progression of myopia; however, randomised controlled trials (RCTs) would be needed to support such routine therapy.

TABLE 1: Review of some studies investigating factors that could influence visual acuity, contrast sensitivity and dry eye disease using both Pearson's and Spearman's correlation coefficients.

\begin{tabular}{|c|c|c|c|c|c|}
\hline Authors & Participants' condition & Visual parameters & Test used & $r$ - and $p$-values & Authors' interpretation \\
\hline Terry et al. ${ }^{27}$ & Fuchs' endothelial dystrophy & Donor corneal thickness and VA & Pearson's correlation & $r=0.236, p<0.001$ & Weak correlation \\
\hline Nejabat et al. ${ }^{28}$ & Keratoconus & $\begin{array}{l}\text { Corneal cylinder and RGP- } \\
\text { corrected VA }\end{array}$ & Pearson's correlation & $r=0.30-0.4, p=0.01$ & A significant relationship \\
\hline Bilen et al. ${ }^{29}$ & Keratoconus & $\begin{array}{l}\text { Refraction and topographic } \\
\text { parameters with VA, CS }\end{array}$ & Spearman correlation & $\begin{array}{l}r=0.30 \text { to } 0.70, p<0.05 \text { for both } \\
\text { VA and CS }\end{array}$ & A significant relationship \\
\hline Kamiya et al..$^{30}$ & Participants after DSAEK & VA with OSI and HOAs & Spearman correlation & $\begin{array}{l}\text { OSI: } r=0.714, p<0.001 \\
\text { HOAs: } r=0.209, p=0.26\end{array}$ & A significant relationship \\
\hline Kawamorita et al. ${ }^{31}$ & Elderly subjects & $\begin{array}{l}\text { Central and peripheral } \\
\text { astigmatism }\end{array}$ & Spearman correlation & $r=0.51, p<0.01$ & A significant relationship \\
\hline Sawada et al. ${ }^{32}$ & $\begin{array}{l}\text { Patient with open angle } \\
\text { glaucoma }\end{array}$ & QoL with VA and loss of VF & Pearson's correlation & $\begin{array}{l}\text { VA: } r=0.1 \text { to } 0.4, p<0.0001 \\
\text { VF: } r=0.4 \text { to } 0.6, p<0.0001 \text { in } \\
10 \text { subscales }\end{array}$ & $\begin{array}{l}\text { VF: good correlation } \\
\text { VA: significant relationship }\end{array}$ \\
\hline Herbaut et al..$^{33}$ & Patients with dry eye & $\begin{array}{l}\text { OSDI with TBUT, Oxford score, } \\
\text { van Bijsterveld score, and } \\
\text { Schirmer test }\end{array}$ & Spearman correlation & $\begin{array}{l}\text { TBUT: } r=-0.21, p=0.013 \\
\text { Oxford score: } r=0.31, p=0.0002 \\
\text { van Bijsterveld score: } r=0.33 \\
p=0.0001 \\
\text { Schirmer test: } r=-0.19, p=0.025\end{array}$ & A significant relationship \\
\hline
\end{tabular}

VA, visual acuity; CS, contrast sensitivity; DSAEK, Descemet's stripping automated endothelial keratoplasty; RGP, rigid gas permeable, HOAs, higher order aberrations; OSI, objective scattering index; OSDI, ocular surface disease index; TBUT, tear film break-up time; VF, visual field; QoL, quality of life. 
TABLE 2: Studies investigating accommodation, visual distortion, myopia, emmetropisation, retinal nerve fibre layer, choroid using both Pearson's and Spearman's correlation coefficients.

\begin{tabular}{|c|c|c|c|c|c|}
\hline Authors & Participants' condition & Visual parameters & Test used & $r$ - and $p$-values & Authors' interpretation \\
\hline Bruce et al. ${ }^{34}$ & Normal subjects & Age with $\mathrm{AC} / \mathrm{A}$ and $\mathrm{CA} / \mathrm{C}$ & Pearson's correlation & $\begin{array}{l}\text { AC/A: } r=0.60, p=0.002 \\
\text { CA/C: } r=0.86, p=0.0001\end{array}$ & $\begin{array}{l}\text { AC/A: Moderate significant } \\
\text { relationship } \\
\text { CA/C: High significant relationship }\end{array}$ \\
\hline Gwiazda et al. ${ }^{35}$ & Myopic subjects & Myopia with accommodation & Pearson's correlation & $r=0.64, p<0.0001$ & Strong correlation \\
\hline Piano et al. ${ }^{36}$ & Adult amblyopes & $\begin{array}{l}\text { Visual distortion with motor } \\
\text { fusion, stereoacuity, near } \\
\text { deviation and amblyopia depth }\end{array}$ & Spearman's correlation & $\begin{array}{l}\text { Motor fusion: } r=-0.417, p=0.043 \\
\text { Stereoacuity: } r=0.492, p=0.015 \\
\text { Near deviation: } r=0.740, p<0.001 \\
\text { Amblyopia depth: } r=0.405, p=0.049\end{array}$ & $\begin{array}{l}\text { Moderate significant relationship } \\
\text { for } r=0.4 \text { and } 0.5 \\
\text { Strong significant relationship for } \\
r=0.7\end{array}$ \\
\hline Hyman et al. ${ }^{37}$ & Myopic children & $\begin{array}{l}\text { Myopia progression with axial } \\
\text { length }\end{array}$ & Pearson's correlation & $r=-0.88 ; p<0.001$ & Significant relationship \\
\hline Aslan et al. ${ }^{42}$ & ADHD subjects & $\begin{array}{l}\text { RNFL thickness with pupillometry } \\
\text { measurements }\end{array}$ & Pearson's correlation & $\begin{array}{l}\text { RE: } r=0.339, p=0.003 \\
\text { LE: } r=0.169, p=0.148\end{array}$ & RE: Significant relationship \\
\hline Katsanos et al. ${ }^{43}$ & $\begin{array}{l}\text { Patient with open } \\
\text { angle glaucoma }\end{array}$ & $\begin{array}{l}\text { RNFL thickness and perimetry } \\
\text { measures }\end{array}$ & Pearson's correlation & $r$ ranging from 0.39 to $0.47, p<0.05$ & Moderate relationship \\
\hline Ye et al. ${ }^{45}$ & Myopic subjects & $\begin{array}{l}\text { Retinal sublayer thickness with } \\
\text { choroid thickness }\end{array}$ & Pearson's correlation & $r=0.403, p<0.001$ & Significant relationship \\
\hline Holm et al. ${ }^{46}$ & $\begin{array}{l}\text { Patients with } \\
\text { non-proliferative } \\
\text { diabetic retinopathy }\end{array}$ & $\begin{array}{l}\text { Foveal thickness with foveal } \\
\text { function }\end{array}$ & Spearman's correlation & $\begin{array}{l}\text { Central area: } r=-0.541 ; p=0.004 \\
\text { Prolonged implicit times: } r=0.548 ; \\
p=0.004 \\
\text { VA: } r=-0.49 ; p=0.045\end{array}$ & Correlation present \\
\hline
\end{tabular}

$\mathrm{RNFL}$, retinal nerve fibre layer; $\mathrm{ADHD}$, attention deficit hyperactivity disorder; $\mathrm{AC} / \mathrm{A}$; accommodative convergence to accommodation ratio; $\mathrm{CA} / \mathrm{C}$, convergence accommodation to convergence; $\mathrm{RE}$, right eye; LE, left eye; $V A$, visual acuity.

Other researchers explored factors that correlated with visual distortions and myopia progression. Piano et al. ${ }^{36}$ reported that visual distortions correlated with motor fusion, log stereoacuity, near angle of heterotrophic or heterophoric deviation and amblyopia depth (Table 2). Furthermore, Hyman et al. ${ }^{37}$ compared 3-year myopia progression with increases in axial length and reported a significant relationship (Table 2). ${ }^{37}$ They also reported age, gender and ethnicities as crucial factors in myopic progression; however, Pearson's correlation was not conducted to explore these relationships. ${ }^{37}$

There were several studies that is directed towards investigating the retinal nerve fibre layer (RNFL), retinal layer thicknesses, foveal thickness, hyper-reflective foci and their correlation with other visual parameters using Pearson's and Spearman's tests. Amanullah et al. ${ }^{38}$ explored the correlation between CS and RNFL thickness in different areas of vision in patients with glaucoma. The authors reported a correlation between the RNFL thickness in the inferior quadrant (RNFL clock hours 5:00-7:00) and the CS score in the left upper area of vision $(r=0.20-0.50, p<0.05$, between four visits). A variation in $r$-values across four visits was observed and only in specific areas of the vision. Therefore, this result might be taken cautiously. However, previous studies suggest reduced CS in glaucomatous patients. ${ }^{39,40}$ Lee et al. $^{41}$ investigated the retinal layer thicknesses and visual function in patients with traumatic optic neuropathy. The most significant relationships reported were with mean deviation in Humphrey field analysis and Visual Field Index in this analysis $(r=0.50-0.70, p<0.05)$. However, some correlation coefficients were found to be $<0.2$ and were not discussed in terms of their strength. Aslan et al. investigated correlations between macular and RNFL thickness parameters with pupillometry measurements of patients with attention deficit hyperactivity disorder (ADHD). ${ }^{42}$ They found a significant relationship in the right eye but a weak and insignificant relationship in the left eye (Table 2). Thus, they suggested that pupillometry measurements may be used as supportive diagnostic tools for ADHD, although the strength of the correlation coefficient was 0.3. Furthermore, Katsanos et al. found an association between the RNFL thickness and perimetry measures. ${ }^{43}$ They reported a moderate relationship, even though the correlation coefficient was $<0.50$ (Table 2). In addition, Balasubramanian et al. explored the relationship between the retinal layer thicknesses and visual function amongst young adults born preterm. The authors reported that the inner retinal layer thickness was 'moderately' correlated with VA $(r=0.30, p<0.001),{ }^{44}$ although the strength of the reported association was mild or fair. Ye et al. reported that the thickness of one outer retinal sublayer (myoid and ellipsoid zone) is significantly correlated with choroid thickness, indicating that thinner choroids are associated with worse vision (Table 2). ${ }^{45}$ However, authors did not report relationships with the other retinal sublayers-outer plexiform layer, Henle fibre layer and outer nuclear layer, outer segment of photoreceptors, and interdigitation zone and RPE-Bruch complex. ${ }^{45}$ The study by Holm et al. investigated the foveal thickness measured by optical coherence tomography (OCT) and foveal function by multifocal electroretinography in patients with nonproliferative diabetic retinopathy. ${ }^{46}$ They reported an inverse relationship with central area of the OCT, with prolonged implicit times, inversely correlated with VA (Table 2). Finally, Piri et al. investigated the relationship between the number of hyper-reflective foci and Stargardt's disease severity in terms of the degree of retinal atrophy, VA and disease duration. ${ }^{47}$ The number of hyper-reflective foci in the Bruch membrane or RPE complex, choriocapillaris, and Sattler's layer increased with decreasing VA $(r=0.9, p<0.05)$. They also reported a correlation between the number of hyperreflective foci in the choriocapillaris and the Sattler layer and disease duration $(r=0.98, p<0.05)$. They did not find any relationship between these variables and best-corrected VA and central macular thickness. However, there were interesting significant relationships observed, which indicate that $98 \%$ of variation is shared. This close relationship means that variables could measure the same parameter, and measuring one variable (i.e. either VA or disease duration) 
TABLE 3: Studies targeting patients with low vision using both Pearson's and Spearman's correlation coefficient tests.

\begin{tabular}{|c|c|c|c|c|c|}
\hline Authors & Participants' condition & Visual parameters & Test used & $r$ - and $p$-values & Authors' interpretation \\
\hline Messias et al. ${ }^{48}$ & Patients with RP & $\begin{array}{l}\text { FST with VF mean deviation, } \\
\text { microperimetry mean threshold, } \\
\text { ERG dark-adapted a-wave } \\
\text { amplitude, b-wave amplitude, } \\
\text { 30-Hz flicker response and ERG } \\
\text { cone b-wave amplitude }\end{array}$ & $\begin{array}{l}\text { Pearson's } \\
\text { correlation }\end{array}$ & $\begin{array}{l}\text { VF mean deviation: } r=-0.4 ; p<0.01 \\
\text { Microperimetry mean threshold: } \\
r=-0.61 ; p<0.01 \\
\text { ERG dark-adapted a-wave amplitude } \\
(r=-0.56 ; p<0.01) \\
\text { b-wave amplitude } \\
(r=-0.64 ; p<0.001) \\
30-\mathrm{Hz} \text { flicker response: } \\
(r=-0.50 ; p<0.01) \\
\text { ERG cone b-wave amplitude: } r=-0.72 ; \\
p<0.01\end{array}$ & $\begin{array}{l}\text { Correlation present in } r=0.4 \\
\text { Moderate correlation in } r=0.5-0.6 \\
\text { High correlation in } r=0.7\end{array}$ \\
\hline Murakami et al. ${ }^{49}$ & Patients with RP & $\begin{array}{l}\text { Aqueous flare with VA and mean } \\
\text { deviation of perimetry test }\end{array}$ & $\begin{array}{l}\text { Spearman's } \\
\text { correlation }\end{array}$ & $\begin{array}{l}\text { VA: } r=0.36, p<0.0001 \\
\text { Mean deviation: } r=-0.33, p<0.0001\end{array}$ & Significantly correlated \\
\hline McMahon et al..$^{50}$ & Patients with ARMD & $\begin{array}{l}\text { Reading rate with saccadic } \\
\text { frequency }\end{array}$ & $\begin{array}{l}\text { Pearson's } \\
\text { correlation }\end{array}$ & $r=-0.795, p<0.05$ & Highly correlated \\
\hline Amore et al. ${ }^{51}$ & Patients with ARMD & $\begin{array}{l}\text { Fixation stability and reading } \\
\text { performance }\end{array}$ & $\begin{array}{l}\text { Pearson's } \\
\text { correlation }\end{array}$ & $\begin{array}{l}2^{\circ} \text { circle: } r=0.74, p<0.01 \\
4^{\circ} \text { circle: } r=0.65, p<0.01\end{array}$ & Significant relationship \\
\hline Cheong et al. ${ }^{52}$ & Patients with ARMD & $\begin{array}{l}\text { Visual span with reading } \\
\text { performance }\end{array}$ & $\begin{array}{l}\text { Spearman's } \\
\text { correlation }\end{array}$ & $\begin{array}{l}\text { Reading speed: } r=0.31, p>0.05 \\
\text { Information transfer rate: } r=0.60, \\
p<0.05 \\
\text { Scotoma size: } r=-0.62, p=0.02 \\
\text { Information transfer: VA: } r=-0.62, \\
p=0.03) \text {, with CS }(r=0.58, p=0.04) \text {, and } \\
\text { with reading acuity }(r=-0.57, p=0.04)\end{array}$ & $\begin{array}{l}\text { Significant relationship and 'strongly } \\
\text { correlated' for correlation coefficients } \\
\text { of } 0.50-0.6\end{array}$ \\
\hline Puell et al. ${ }^{53}$ & Patients with ARMD & Macular pigment and VA & $\begin{array}{l}\text { Pearson's } \\
\text { correlation }\end{array}$ & $r=-0.47, p=0.0008$ & $\begin{array}{l}\text { Significant relationship } \\
\text { Explained in discussion that ' } r \text { values } \\
\text { ranged from } 0.47 \text { to } 0.46 \text { such that the } \\
\text { observed relationships could only } \\
\text { explain } 22.2 \%-21.7 \% \text { of the variability' }\end{array}$ \\
\hline Chen et al. ${ }^{55}$ & $\begin{array}{l}\text { Patients with idiopathic } \\
\text { macular epi-retinal } \\
\text { membranes }\end{array}$ & Central fovea thickness and VA & $\begin{array}{l}\text { Pearson's } \\
\text { correlation }\end{array}$ & $r=0.35, p=0.03$ & Significant relationship \\
\hline
\end{tabular}

RP, retinitis pigmentosa; ARMD, age-related macular degeneration; FST, full-field stimulus threshold; VF, visual field; ERG, electroretinogram; VA, visual acuity.

could be sufficient to assess disease severity and could also be more cost effective.

Several studies investigating patients with low vision were reviewed. Messias et al. explored the relationship between the VF and electroretinography indices in patients with retinitis pigmentosa (RP). ${ }^{48}$ The authors reported inverse correlations between these measurements (Table 3). Furthermore, Messias et al.'s. study was one of the few studies that described, in their statistical methods, the classification used in reporting the strength of the correlation coefficients. ${ }^{48}$ Murakami et al.'s study investigated relationships between aqueous flare and VA and mean deviation (MD) of static perimetry test in RP patients. ${ }^{49}$ They observed that aqueous flare values are correlated with VA and MD (Table 3). McMahon et al., ${ }^{50}$ explored the relationship between the reading rate and saccadic frequency in patients with age-related macular degeneration (ARMD). Log reading rates of patients were highly correlated with the re-fixation rate for five-letter task scores, indicating a strong association between the saccadic frequency in a sequencing task and patient reading rates (Table 3 ). Amore et al. explored the relationship between fixation stability and reading performance in ARMD.${ }^{51}$ They reported that reduced reading performance is significantly correlated with fixation instability (Table 3). ${ }^{51}$ Cheong et al. investigated the relationship between visual span and reading performance in ARMD. ${ }^{52}$ They stated that reading speed did not correlate with visual span size (Table 3). However, reading speed was correlated with information transfer rate, and visual span size was also related to scotoma size (Table 3). They also suggested that slower information transfer in patients with ARMD is correlated with VA, CS and reading acuity (Table 3). ${ }^{52}$ Puell et al. ${ }^{53}$ explored the relationship between macular pigment and VA in patients with ARMD, and reported a significant relationship for both high- and lowcontrast VA, indicating that when macular pigment increases, VA improves (Table 3). However, this result was not different from that of subjects in the control group. Thus, macular pigment is a fundamental factor for VA, and in advanced stages of ARMD (with MP values < 0.3 optical density), VA is expected to deteriorate. The study by Puell et al. was one of the few studies that explained their correlation coefficients and revealed, ' $r$ values ranged from 0.47 to 0.46 such that the observed relationships could only explain $22.2 \%-21.7 \%$ of the variability'. Tolman et al. reported a mild significant relationship between psychosocial adaptation to vision loss and its relationship with depressive symptomatology in legally blind older adults with ARMD. ${ }^{54}$ However, low correlation coefficients were also suggested as significant but $r$ was $<0.30$, indicating a relatively poor relationship. Chen et al. ${ }^{55}$ reported a relationship between post-operative central fovea thickness and post-operative best-corrected VA in patients with idiopathic macular epi-retinal membranes (Table 3). However, a comparison with outcomes of surgery without internal limiting membrane peeling was not made, and therefore, the authors' suggestion could be inconclusive.

Other studies investigated factors related to refractive status, although their interpretations were not largely conforming to the strength of the founded correlation coefficients. For example, the study by Mutti et al. ${ }^{56}$ provides a good example of mixed interpretation of correlation values. They reported a significant correlation between residuals from the orthogonal regression at the age of 3 months with Mohindra retinoscopy $(r=0.22, p=0.001)$ and dynamic retinoscopy $(r=0.15$, $p=0.036)$. They concluded, 'more hyperopic levels of 
defocus at distance and close up were associated with poorer emmetropisation than that predicted by the underlying level of wet spherical equivalent refractive error of the right eye'. The authors also reported that worse VA at 3 months of age was related to more hyperopic wet spherical errors at 18 months $(r=0.18, p=0.021)$, although these low $r$-values signify no such clinically significant relationship. These results reveal only $2 \%-4 \%$ of shared variation. However, Mutti et al. ${ }^{56}$ reported an interesting significant relationship between the change of refractive errors at the age of 3 months and a total accommodative response at near and far distances $(r=0.41, p<0.0001, r=0.36, p<0.0001)$. Furthermore, they reported a correlation between total accommodative response at near and far with wet spherical equivalent refractive error ( $r=0.51, r=0.47, p<0.0001$, for both). Lauriola ${ }^{57}$ investigated the relationship between psychological parameters and child refraction but likewise included mixed interpretations of correlation values. ${ }^{57}$ They reported a 'large' correlation in refraction between a mother and child, although the value was only 0.3 , indicating a low or mild relationship. They also reported a significant correlation between myopia, introversion and mental closeness ( $r$ was $-0.15,-0.12, p<$ 0.01 , respectively); however, these relationships indicate only $1 \%-2 \%$ shared variances, which point to a relatively poor or negligible relationship.

Similarly, Khojasteh et al. reported a significant relationship between one multifocal electroretinogram parameter and OCT in the eyes of patients with diabetic macular oedema. ${ }^{58}$ Although the $r$-value was only 0.06 (shared variance of $0.0018 \%$ ), such reporting highlights the importance of interpreting $r$-values in a systematic fashion. This study also reported an $r$-value of 0.48 in the same manner as the $r$-value of 0.06 without discussing percentages of shared variance..$^{58}$ Similarly, Zheng et al.'s study reported that baseline and best-corrected VA levels correlated with baseline depressive symptoms ( $r=0.14, p<0.001, r=0.17, p=0.01$, respectively) despite low $r$-values. ${ }^{59}$ Moreover, Kattan et al. investigated the relationship between binocular summation and stereoacuity after strabismus surgery. ${ }^{60}$ The authors reported a significant relationship between Sloan low-contrast acuity (LCA, 2.5\% and 1.25\%) and near and distant stereoacuity based on $r$-values ranging from -0.18 to $0.24(p<0.05)$, which actually indicates a poor relationship. Relationship strength was not fully discussed in these studies, and the percentage of shared variance was not included..$^{58,60}$ Finally, Leray et al. suggested that modification of corneal asphericity to induce spherical aberration (SA) can improve the depth of focus in hyperopic LASIK based on outcomes in the relationship between spherical aberration and changes in pseudoaccommodation values for intermediate $(r=-0.320, p<0.01$ for negative SA; $r=0.270, p<0.05$ for positive SA) and near vision $(r=-0.348, p<0.01$, and $r=0.268, p<0.05$, respectively). ${ }^{61}$ The strength of coefficients was mild at best; yet, the authors suggested that aspheric hyperopic LASIK can increase the depth of focus. Experts and reviewers in the field could suggest a cut-off point for correlation coefficient to limit recommendations for changes to surgical procedures or invasive interventions. Comparatively, one of the few studies that discussed the proper interpretation of $r^{2}$ is Masters et al. ${ }^{90}$, where the authors discussed that variables showing a correlation coefficient of $r=0.37$ share only $14.7 \%$ of the variance, and therefore, concluded that although, there was a correlation but it is not the main determinant of the investigated outcome and the result was not conclusive.

Several studies reviewed and investigated the relationship of ocular measurements with various ocular factors and did not find any evidence of relationship between them, which are demonstrated in detail (Table 4). ${ }^{62,63,64,65,66,67,68,69,70}$ These studies investigated, for example, patients with myopia, dryness symptoms and keratoconus, and patients with AMD and QoL of patients.

\section{Ethical considerations}

The author confirms that ethical clearance was not needed for this review. This study followed all ethical standards for research without direct contact with human or animal subjects.

TABLE 4: Studies that investigated ophthalmic data using both Pearson's and Spearman's correlation coefficient tests and did not find relationships.

\begin{tabular}{|c|c|c|c|c|c|}
\hline Authors & Participants' condition & Visual parameters & Test used & $r$ - and $p$-values & Authors' interpretation \\
\hline Koomson et al. ${ }^{62}$ & Myopic children & $\begin{array}{l}\text { Accommodative lag and } \\
\text { myopia progression }\end{array}$ & Pearson's correlation & $\begin{array}{l}\text { FC: } r=0.02, p=0.49 \\
\text { UC: } r=0.04, p=0.49\end{array}$ & No significant relationship \\
\hline Nicholas et al..$^{63}$ & Patients with keratoconus & TMH and dryness symptoms & Pearson's correlation & $r=0.0392, p=0.85$ & $\begin{array}{l}\text { Poor and non-significant } \\
\text { correlation }\end{array}$ \\
\hline Prasad et al. ${ }^{64}$ & Healthy subjects & Age and refraction, with $\mathrm{CCT}$ & Not Specified & $\begin{array}{l}\text { Refraction: } r=0.02, p>0.05 \\
\text { Age: } r=0.10, p>0.05\end{array}$ & No significant relationship \\
\hline Zeri et al. ${ }^{65}$ & Young adults & $\begin{array}{l}\text { Stability of ocular dominance } \\
\text { and reading deficits }\end{array}$ & Spearman's correlation & $\begin{array}{l}\text { Reading time: } r=0.02, p>0.05 \\
\text { Reading accuracy: } r=0.02 \\
p>0.05\end{array}$ & No significant relationship \\
\hline Wang et al..$^{66}$ & Healthy subjects & $\begin{array}{l}\text { Sensory eye dominance and } \\
\text { stereopsis in }\end{array}$ & Spearman's correlation & $\begin{array}{l}\text { Balance point: } r=0.14, p=0.10 \\
\text { Phase: } r=0.13, p=0.13\end{array}$ & No significant relationship \\
\hline Kříž et al. ${ }^{67}$ & Healthy subjects & $\begin{array}{l}\text { Heterophoria with refractive } \\
\text { error and age }\end{array}$ & Not specified & $r=0.10, p>0.05$ & No significant relationship \\
\hline Boxerman and Wittich ${ }^{68}$ & Patients with ARMD & $\mathrm{CBS}$ with depression and $\mathrm{MCl}$ & Pearson's correlation & $r=0.10$ to $0.20, p>0.05$ & No significant relationship \\
\hline Olaniyan et al. ${ }^{69}$ & $\begin{array}{l}\text { Patients with diabetes } \\
\text { mellitus. }\end{array}$ & $\begin{array}{l}\text { Dry eye with glycosylated } \\
\text { haemoglobin }\end{array}$ & Spearman's correlation & $r=0.10, p>0.05$ & No significant relationship \\
\hline Lee et al. ${ }^{70}$ & $\begin{array}{l}\text { Patients with diabetes } \\
\text { mellitus. }\end{array}$ & $\begin{array}{l}\text { QoL scores with VA and } \\
\text { Amsler field }\end{array}$ & Pearson's correlation & $r=0.10, p>0.05$ & No significant relationship \\
\hline
\end{tabular}

ARMD, age-related macular degeneration; CCT, central corneal thickness; TMH, tear meniscus height; CBS, Charles Bonnet syndrome; MCl, mild cognitive impairment; QoL, quality of life; VA, visual acuity. 

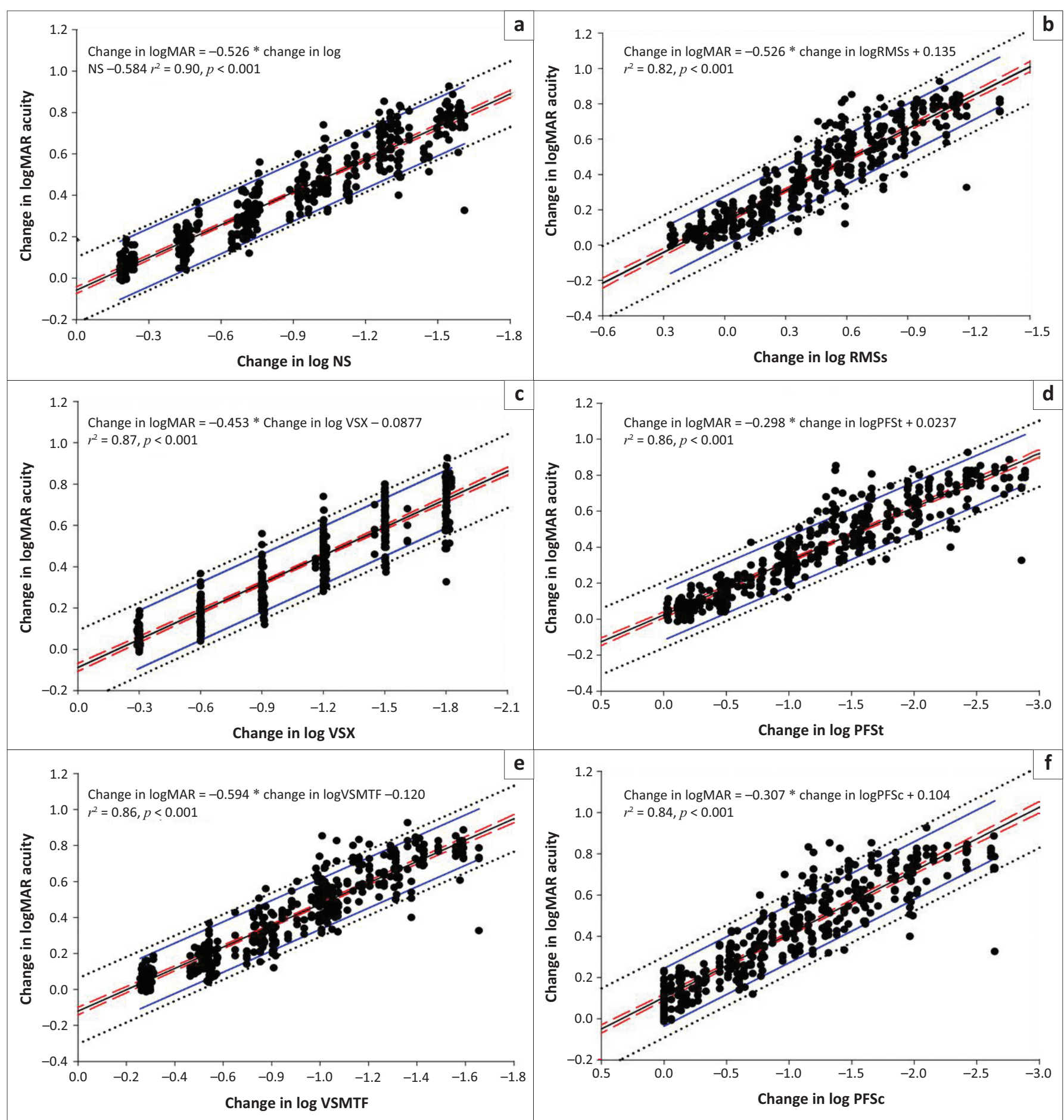

Source: Adapted from Ravikumar A, Sarver EJ, Applegate RA. Change in visual acuity is highly correlated with change in six image quality metrics independent of wavefront error and/or pupi diameter. J Vis. 2012;12(10):11. https://doi.org/10.1167/12.10.11

NS, neural sharpness; RMSs, root mean square of wavefront error slope; VSX, visual Strehl calculated in spatial domain; PFSt, pupil fraction tessellated ; VSMTF, visual Strehl calculated by image plane metrics with neural filters; PFSc, pupil fraction as concentric area; logMAR, logarithm of the minimum angle of resolution.

FIGURE 1: The scatterplots demonstrate the change in visual acuity as a function of change in six quality metrics. The central black line represents the best-fitting regression line, and the black dotted line represents the $95 \%$ confidence interval defined by the data. The red dashed lines represent the $95 \%$ confidence interval for the regression, while blue lines represent the $95 \%$ confidence interval from the regression line for clinically significant change in acuity as defined by Arditi and Cagenello (1993). ${ }^{84}$

\section{Discussion}

This study aimed to present and discuss methods for investigating and interpreting Pearson's and Spearman's correlations in ophthalmic data. Most reviewed studies did not discuss strengths of relationships, did not report assessment of normality of data distribution, did not report the basis for choosing Pearson's correlation coefficient or Spearman test and at times used contrasting interpretations of correlation coefficients.

One of the interesting observations whilst reviewing these papers was that some studies did not report or comment on the strength of significant relationships. ${ }^{71,72,73,74,75,76,77,78,79,80,81}$ 


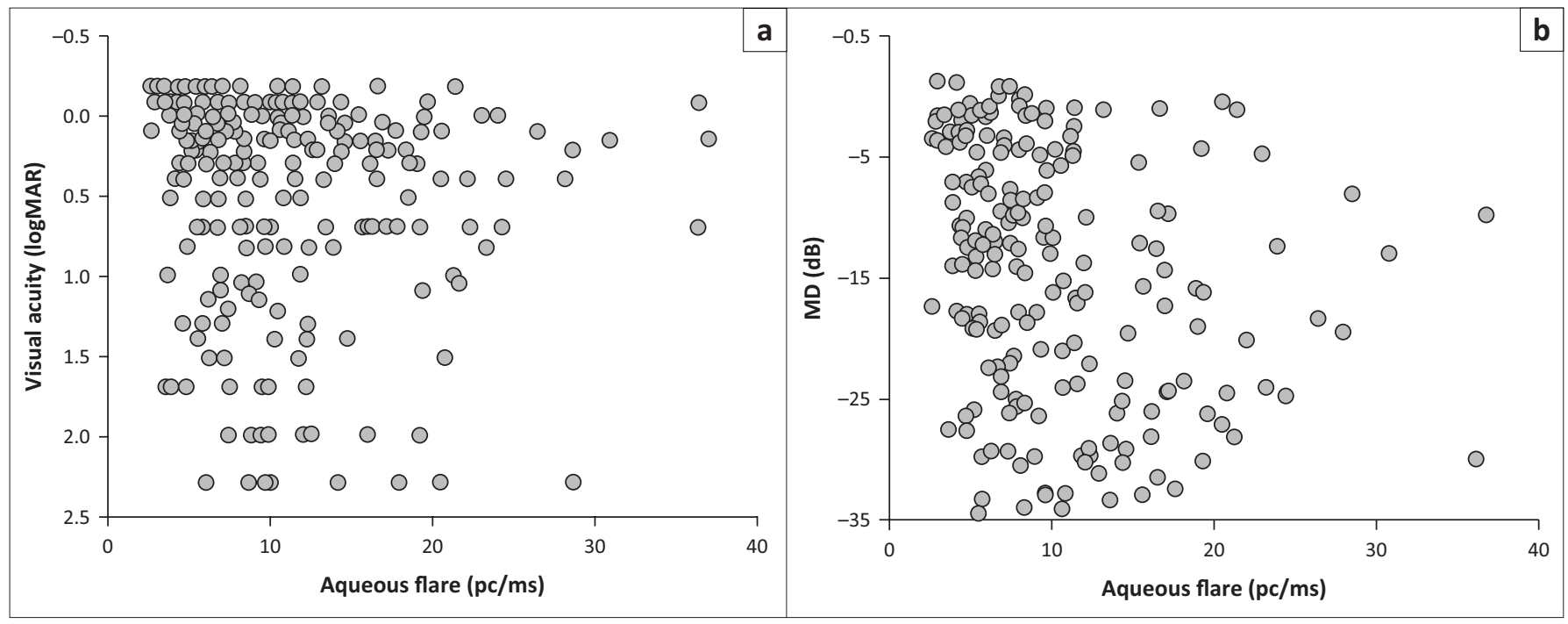

Source: Adapted from Murakami Y, Yoshida N, Ikeda Y, et al. Relationship between aqueous flare and visual function in retinitis pigmentosa. Am J Ophthalmol. 2015;159(5):958-963. https://doi. org/10.1016/j.ajo.2015.02.001

logMAR, logarithm of the minimum angle of resolution; $\mathrm{pc} / \mathrm{mc}$, photon counts per millisecond.

FIGURE 2: (a) Scatterplot illustrating relationship between aqueous flare and central visual function in patients with retinitis pigmentosa $(r=0.359, p<0.0001)$. (b) Scatterplot of aqueous flare values and mean deviation on the Humphrey Field Analyzer 10-2 program $(r=0.330, p<0.0001)$.

Furthermore, other studies focused more on finding a significant $p$-value than on relationship strength. ${ }^{82,83}$ This misuse may indicate a need for standardised criteria for interpreting correlation coefficient relationships. Additionally, authors would need to discuss findings in terms of their clinical significance and implications. The statistical significance mainly indicates the reliability of the study data, whilst the clinical significance reflects its impact on professional in clinical practice. ${ }^{85,86}$ Whereas statistical significance depends heavily on the sample size, in studies with large sample sizes, even small difference between groups can appear to be statistically significant. ${ }^{85}$ Therefore, the clinical practitioner has to interpret cautiously whether this statistical significance has any clinical impact. ${ }^{85}$ In some studies, the difference might be relatively miniscule, which might not lead to a decision to change the current clinical practice. ${ }^{87,88}$ It has been suggested that the clinical significance could be reflected into the extent of change, whether the change makes a marked difference to patients' lives, consumer acceptability, cost-effectiveness and ease of implementation. ${ }^{89}$ However, deciding the cut-off point for clinical significance is usually based on the judgement of the clinician, patients' preferences, side-effect profiles and the economic factor. ${ }^{85,87} \mathrm{In}$ this review, the studies overwhelmingly did not include the clinical significance as a main part of their discussion. In the peer-review process for medical journals, the authors shall be requested for more in-depth discussion of the clinical implication of their findings and relative to their reported statistical significance.

One of the more important issues in investigating relationship is plotting data in graphs, which is the first best step before performing any numerical analysis., ${ }^{3,15}$ Such plots may help authors to avoid misusing correlation coefficients for relationships, which are not adequately characterised by the analysis. ${ }^{3}$ Schober et al. ${ }^{3}$ present examples of these relationships (e.g. see Schober et al. Figures 2A, 3A, and 3B-D). ${ }^{3}$ Researchers should not depend only on correlation coefficient values in isolation but should plot data for a visual inspection of the relationship. ${ }^{3,15}$ Scatter plot analysis might show a monotonic trend, a good example of which is presented by Ravikumar et al. ${ }^{90}$ (Figure 1, adapted with permission from their papers). Another example could be seen in the Murakami et al.'s study, where aqueous flare correlations with VA and MD demonstrate how a scatter plot illustrates the true strength of a relationship and to what extent variance is shared (Figure 2, adapted with permission from their papers). ${ }^{49}$ The figure in Murakami et al.'s study shows that where aqueous flare is $<10$, most participants are $<50$ years old, indicating a confounding factor of age and explaining why only $10 \%$ of the variance is explained by the association. A more appropriate analysis might be obtained with additional participants recruited in the $50+$ age group, and a stronger relationship might be observed.

In conclusion, this review focuses on the use of Pearson's and Spearman's statistical tests for assessing relationships in ophthalmic data and methods of interpretation and reporting. A peer review of studies that present correlations should require authors to report normality of their data, $r$-values, $p$-values and to what degree the association explains the variance between two factors or measures. Furthermore, the clinical implication of their findings should be stated clearly, and an in-depth discussion would be preferable. Finally, association does not imply causation, and more detailed analysis can be obtained by regression.

\section{Acknowledgements}

The author extends his appreciation to the College of Applied Medical Sciences Research Centre and the Deanship of Scientific Research at King Saud University for funding this research study. The author would like to thank the RSSU at King Saud University for their technical support. 


\section{Competing interests}

The author declares that he has no financial or personal relationships that may have inappropriately influenced him in writing this research article.

\section{Authors' contributions}

The author was responsible for the manuscript conception, research, analysis and for writing the research article.

\section{Funding information}

This research study received funding from the College of Applied Medical Sciences Research Centre and the Deanship of Scientific Research at King Saud University.

\section{Data availability}

Data sharing is not applicable to this article.

\section{Disclaimer}

The views and opinions expressed in this research article are those of the author and do not necessarily reflect the official policy or position of any affiliated agency of the author.

\section{References}

1. Hauke J, Tomasz K. Comparison of values of Pearson's and Spearman's correlation coefficients on the same sets of data. Quaest Geogr. 2011;30(2):87-93. https:// doi.org/10.2478/v10117-011-0021-1

2. Rebekic A, Loncaric Z, Petrovic S, Maric S. Pearson's or Spearman's correlation coefficient - Which one to use? Poljoprivreda. 2015;21(2):47-54. https://doi. org/10.18047/poljo.21.2.8

3. Schober P, Boer C, Schwarte LA. Correlation coefficients: Appropriate use and interpretation. Anesth Analg. 2018;126(5):1763-1768. https://doi.org/10.1213/ ANE.0000000000002864

4. Yadav S. Correlation analysis in biological studies. J Pract Cardiovasc Sci. 2018;4(2):116-121. https://doi.org/10.4103/jpcs.jpcs_31_18

5. Gauthier TD. Detecting trends using Spearman's rank correlation coefficient Environ Forens. 2001;2(4):359-362. https://doi.org/10.1006/enfo.2001.0061

6. Ly A, Marsman M, Wagenmakers E-J. Analytic posteriors for Pearson's correlation coefficient. Stat Neerl. 2018;72(1):4-13. https://doi.org/10.1111/stan.12111

7. Artusi R, Verderio P, Marubini E. Bravais-Pearson and Spearman correlation coefficients: Meaning, test of hypothesis and confidence interval. Int J Biol
Markers. 2002;17(2):148-151. https://doi.org/10.1177/172460080201700213

8. Miot HA. Correlation analysis in clinical and experimental studies. J Vasc Brasil. 2018;17(4):275-279. https://doi.org/10.1590/1677-5449.174118

9. Akoglu $H$. User's guide to correlation coefficients. Turk J Emerg Med. 2018;18(3):91-93. https://doi.org/10.1016/j.tjem.2018.08.001

10. Taylor R. Interpretation of the correlation coefficient: A basic review. J Diagn Med Sonogr. 1990;6(1):35-39. https://doi.org/10.1177/875647939000600106

11. Heiman GW. Correlation coefficients. In: Basic statistics for the behavioral sciences. Wadsworth Cengage Learning; Boston, MA: Gary W. Heiman, 2011; p. $135-160$.

12. Mukaka MM. Statistics corner: A guide to appropriate use of correlation coefficient in medical research. Malawi Med J. 2012;24(3):69-71.

13. Hinkle DE, Wiersma W, Jurs SG. Applied statistics for the behavioral sciences. Boston, MA: Houghton Mifflin; 2003.

14. Overholser BR, Sowinski KM. Biostatistics primer: Part 2. Nutr Clin Pract 2008;23(1):76-84. https://doi.org/10.1080/10408340500526766

15. Asuero AG, Sayago A, Gonzalez AG. The correlation coefficient: An overview. Crit Rev Anal Chem. 2006;36(1):41-59. https://doi.org/10.1080/10408340500526766

16. Mondal S, Mondal $\mathrm{H}$. Value of $\mathrm{r}(2)$ in statistical analysis by Pearson correlation coefficient. J Clin Diagn Res. 2017;11(11):CL1. https://doi.org/10.7860/JCDR/ 2017/29763.10812

17. Browner WS, Newman TB, Hulley SB. Estimating sample size and power: Applications and example. In. Hulley SB, editor. Hulley, Designing clinical research. Philadelphia, PA: Lippincott Williams \& Wilkins, 2001; p. 65-93.

18. Aggarwal R, Ranganathan P. Common pitfalls in statistical analysis: The use of correlation techniques. Perspect Clin Res. 2016;7(4):187-190. https://doi. org/10.4103/2229-3485.192046
19. Walpole RE, Myers RH, Myers SL, Ye K. Simple linear regression and correlation. In: Lynch D, editor. Probability \& statistics for engineers \& scientists. Boston, MA: Pearson Education, 2012; p. 430-433.

20. Greenland S, Senn SJ, Rothman KJ, et al. Statistical tests, P values, confidence intervals, and power: A guide to misinterpretations. Eur J Epidemiol. 2016; 31(4):337-350. https://doi.org/10.1007/s10654-016-0149-3

21. Trafimow D, Marks M. Editorial. Basic Appl Soc Psychol. 2015;37(1):1-2. https:// doi.org/10.1080/01973533.2015.1012991

22. Nahm FS. What the $P$ values really tell us. Korean J Pain. 2017;30(4):241-242. https://doi.org/10.3344/kjp.2017.30.4.241

23. Dahiru T. P-value, a true test of statistical significance? A cautionary note. Ann Ib Postgrad Med. 2008;6(1):21-26. https://doi.org/10.4314/aipm.v6i1.64038

24. Fisher RA. Statistical methods for research workers. London: Oliver and Boyd; 1970.

25. Wasserstein RL, Lazar NA. The ASA statement on p-values: Context, process, and purpose. Am Stat. 2016;70(2):129-133. https://doi.org/10.1080/00031305.2016. 1154108

26. Moher D, Liberati A, Tetzlaff J, Altman DG. Preferred reporting items for systematic reviews and meta-analyses: The PRISMA statement. Int J Surg. 2010;8(5):336-341. https://doi.org/10.1016/j.ijsu.2010.02.007

27. Terry MA, Straiko MD, Goshe JM, Li JY, Davis-Boozer D. Descemet's stripping automated endothelial keratoplasty: The tenuous relationship between donor thickness and postoperative vision. Ophthalmology. 2012;119(10):1988-1996. https://doi.org/10.1016/j.ophtha.2012.05.021

28. Nejabat M, Khalili MR, Dehghani C. Cone location and correction of keratoconus with rigid gas-permeable contact lenses. Cont Lens Anterior Eye. 2012;35(1): 17-21. https://doi.org/10.1016/j.clae.2011.08.007

29. Bayraktar Bilen N, Hepsen IF, Arce CG. Correlation between visual function and refractive, topographic, pachymetric and aberrometric data in eyes with keratoconus. Int J Ophthalmol. 2016;9(8):1127-1133.

30. Kamiya K, Asato H, Shimizu K, Kobashi H, Igarashi A. Effect of intraocular forward scattering and corneal higher-order aberrations on visual acuity after Descemet's stripping automated endothelial keratoplasty. PLoS One. 2015;10(6):e0131110. stripping automated endothelial keratoplasty.
https://doi.org/10.1371/journal.pone.0131110

31. Kawamorita T, Shimizu K, Hoshikawa R, Kamiya K, Shoji N. Relationship between central and peripheral corneal astigmatism in elderly patients. Opt Rev. 2018; 25:336. https://doi.org/10.1007/s10043-018-0427-2

32. Sawada $\mathrm{H}$, Fukuchi $\mathrm{T}$, Abe $\mathrm{H}$. Evaluation of the relationship between quality of vision and the visual function index in Japanese glaucoma patients. Graefes Arch Clin Exp Ophthalmol. 2011;249(11):1721-1727. https://doi.org/10.1007/s00417-011-1779-5

33. Herbaut $A$, Liang $H$, Rabut $G$, et al. Impact of dry eye disease on vision quality: An optical quality analysis system study. TransI Vis Sci Technol. 2018;7(4):5. https:// doi.org/10.1167/tvst.7.4.5

34. Bruce AS, Atchison DA, Bhoola H. Accommodation convergence relationships and age. Investig Ophthalmol Vis Sci. 1995;36(2):406-413

35. Gwiazda J, Bauer J, Thorn F, Held R. A dynamic relationship between myopia and blur-driven accommodation in school-aged children. Vision Res. 1995;35(9): 1299-1304. https://doi.org/10.1016/0042-6989(94)00238-H

36. Piano MEF, Bex PJ, Simmers AJ. Perceptual visual distortions in adult amblyopia and their relationship to clinical features. Investig Ophthalmol Vis Sci. 2015;56(9):5533-5542. https://doi.org/10.1167/iovs.15-17071

37. Hyman L, Gwiazda J, Hussein M, et al. Relationship of age, sex, and ethnicity with myopia progression and axial elongation in the correction of myopia evaluation trial. Arch Ophthalmol. 2005;123(7):977-987. https://doi.org/ evaluation trial. Arch Ophthal
10.1001/archopht.123.7.977

38. Amanullah S, Okudolo J, Rahmatnejad K, et al. The relationship between contrast sensitivity and retinal nerve fiber layer thickness in patients with glaucoma. Graefes Arch Clin Exp Ophthalmol. 2017;255(12):2415-2422. https://doi.org/ Graefes Arch Clin Exp Ophthal
10.1007/s00417-017-3789-4

39. Hawkins AS, Szlyk JP, Ardickas Z, Alexander K, Wilensky J. Comparison of contrast sensitivity, visual acuity, and Humphrey visual field testing in patients with glaucoma. J Glaucoma. 2003;12(2):134-138. https://doi.org/10.1097/00061198200304000-00008

40. Richman J, Lorenzana LL, Lankaranian D, et al. Importance of visual acuity and contrast sensitivity in patients with glaucoma. Arch Ophthalmol. 2010;128(12): 1576-1582. https://doi.org/10.1001/archophthalmol.2010.275

41. Lee J-Y, Cho K, Park K-A, Oh SY. Analysis of retinal layer thicknesses and their clinical correlation in patients with traumatic optic neuropathy. PLOS One. 2016;11(6):e0157388-e0157388. https://doi.org/10.1371/journal.pone.0157388

42. Aslan MG, Uzun F, Findik H, Kaçar M, Okutucu M, Hocaoğlu C. Pupillometry measurement and its relationship to retinal structural changes in children with attention deficit hyperactivity disorder. Graefes Arch Clin Exp Ophthalmol. 2020;258(6):1309-1317. https://doi.org/10.1007/s00417-020-04658-z

43. Katsanos A, Labiris G, Fanariotis M, Tsirouki T, Chatzoulis D. The relationship between Rarebit perimetry and OCT-derived retinal nerve fibre layer thickness in glaucoma. Acta Ophthalmol. 2008;86(8):871-876. https://doi.org/10.1111/j.1755-3768. 2007.01150.x

44. Balasubramanian S, Beckmann J, Mehta H, et al. Relationship between retinal thickness profiles and visual outcomes in young adults born extremely preterm: The EPICure@19 study. Ophthalmology. 2019;126(1):107-112. https://doi. org/10.1016/j.ophtha.2018.07.030

45. Ye J, Shen M, Huang S, et al. Visual acuity in pathological myopia is correlated with the photoreceptor Myoid and Ellipsoid zone thickness and affected by choroid thickness. Invest Ophthalmol Vis Sci. 2019;60(5):1714-1723. https://doi.org/ 10.1167/iovs.18-26086 
46. Holm K, Larsson J, Lövestam-Adrian M. In diabetic retinopathy, foveal thickness of 300 mum seems to correlate with functionally significant loss of vision. Doc Ophthalmol. 2007;114(3):117-124. https://doi.org/10.1007/s10633-006-9044-7

47. Piri N, Nesmith BL, Schaal S. Choroidal hyperreflective foci in Stargardt disease shown by spectral-domain optical coherence tomography imaging: Correlation with disease severity. JAMA Ophthalmol. 2015;133(4):398-405. https://doi. org/10.1001/jamaophthalmol.2014.5604

48. Messias K, Jägle $H$, Saran R, et al. Psychophysically determined full-field stimulus thresholds (FST) in retinitis pigmentosa: Relationships with electroretinography and visual field outcomes. Doc Ophthalmol. 2013;127(2):123-129. https://doi. org/10.1007/s10633-013-9393-y

49. Murakami $Y$, Yoshida N, Ikeda $Y$, et al. Relationship between aqueous flare and visual function in retinitis pigmentosa. Am J Ophthalmol. 2015;159(5):958-963. https://doi.org/10.1016/j.ajo.2015.02.001

50. McMahon TT, Hansen M, Viana M. Fixation characteristics in macular disease. Relationship between saccadic frequency, sequencing, and reading rate. Invest Ophthalmol Vis Sci. 1991;32(3):567-574.

51. Amore FM, Fasciani $R$, Silvestri $V$, et al. Relationship between fixation stability measured with MP-1 and reading performance. Ophthalmic Physiol Opt. 2013;33(5):611-617. https://doi.org/10.1111/opo.12048

52. Cheong AM, Legge GE, Lawrence MG, Cheung SH, Ruff MA. Relationship between visual span and reading performance in age-related macular degeneration. Vision Res. 2008;48(4):577-588. https://doi.org/10.1016/j.visres.2007.11.022

53. Puell MC, Palomo-Alvarez C, Barrio AR, Gómez-Sanz FJ, Pérez-Carrasco MJ. Relationship between macular pigment and visual acuity in eyes with early agerelated macular degeneration. Acta Ophthalmol. 2013;91(4):10. https://doi. org/10.1111/aos.12067

54. Tolman J, Hill RD, Kleinschmidt JJ, Gregg CH. Psychosocial adaptation to visual impairment and its relationship to depressive affect in older adults with agerelated macular degeneration. Gerontologist. 2005;45(6):747-753. https://do org/10.1093/geront/45.6.747

55. Chen L, Liu M, Xie A-M, Liu Y. A study on change of macular retinal thickness and its relationship with vision before and after operation to idiopathic macular epiretinal membranes. Int J Clin Exp Med. 2015;8(10):18571-18580.

56. Mutti DO, Mitchell GL, Jones LA, et al. Accommodation, acuity, and their relationship to emmetropization in infants. Optom Vis Sci. 2009;86(6):666-676. https://doi.org/10.1097/OPX.0b013e3181a6174f

57. Lauriola M. Psychological correlates of eye refractive errors. Pers Individ Dif. 1997;23(5):917-920. https://doi.org/10.1016/S0191-8869(97)00087-1

58. Khojasteh $\mathrm{H}$, Riazi-Esfahani $\mathrm{H}$, Khalili Pour $\mathrm{E}$, et al. Multifocal electroretinogram in diabetic macular edema and its correlation with different optical coherence tomography features. Int Ophthalmol. 2020;40(3):571-581. https://doi.org/10.1007/ s10792-019-01215-4

59. Zheng DD, Bokman CL, Lam BL, et al. Longitudinal relationships between visual acuity and severe depressive symptoms in older adults: The Salisbury Eye acuity and severe depressive symptoms in older adults: The Salisbury Eye
Evaluation study. Aging Ment Health. 2016;20(3):295-302. https://doi.org/ Evaluation study. Aging Ment
$10.1080 / 13607863.2015 .1008985$

60. Kattan JM, Velez FG, Demer JL, Pineles SL. Relationship between binocular summation and stereoacuity after strabismus surgery. Am J Ophthalmol. 2016;165:29-32. https://doi.org/10.1016/j.ajo.2016.02.020

61. Leray B, Cassagne M, Soler V, et al. Relationship between induced spherical aberration and depth of focus after hyperopic LASIK in presbyopic patients. Ophthalmology. 2015;122(2):233-243. https://doi.org/10.1016/j.ophtha.2014.08.021

62. Koomson NY, Amedo AO, Opoku-Baah C, Ampeh PB, Ankamah E, Bonsu. Relationship between reduced accommodative lag and myopia progression. Optom Vis Sci. 2016;93(7):683-691. https://doi.org/10.1097/OPX.0000000000000867

63. Nicholas DL, Gillan WDH. An investigation of the relationship between tear meniscus height and the subjective severity of ocular symptoms in keratoconus.
Afr Vision Eye Health. 2015;74(1):a306. https://doi.org/10.4102/aveh.v74i1.306

64. Prasad A, Fry K, Hersh PS. Relationship of age and refraction to central corneal thickness. Cornea. 2011;30(5):553-555. https://doi.org/10.1097/ICO.0b013 e3181fb880c

65. Zeri F, De Luca M, Spinelli D, Zoccolotti P. Ocular dominance stability and reading skill: A controversial relationship. Optom Vis Sci. 2011;88(11):1353-1362. https:// doi.org/10.1097/OPX.0b013e318229635a

66. Wang Y, Cui L, He Z, et al. On the relationship between sensory eye dominance and stereopsis in the normal-sighted adult population: Normative data. Front Hum Neurosci. 2018;12:357. https://doi.org/10.3389/fnhum.2018.00357

67. Kříž P, Skorkovská Š. Distance associated heterophoria measured with polarized cross test of MKH method and its relationship to refractive error and age. Clin Optom (Auckl). 2017;9:55-65. https://doi.org/10.2147/OPTO.S123436

68. Boxerman $\mathrm{H}$, Wittich $\mathrm{W}$, Overbury $\mathrm{O}$. Charles Bonnet syndrome in older adults with age-related macular degeneration: Its relationship to depression and mild cognitive impairment. Br J Vis Impair. 2015;33(1):19-30. https://doi.org/ $10.1177 / 0264619614557529$
69. Olaniyan SI, Fasina O, Bekibele CO, Ogundipe AO. Relationship between dry eye and glycosylated haemoglobin among diabetics in Ibadan, Nigeria. Pan Afr Med J. 2019;33:14. https://doi.org/10.11604/pamj.2019.33.14.14074

70. Lee PP, Whitcup SM, Hays RD, Spritzer K, Javitt J. The relationship between visual acuity and functioning and well-being among diabetics. Qual Life Res. 1995;4(4):319-323. https://doi.org/10.1007/BF01593884

71. Senger C, Da Silva MJL, De Moraes CG, Messias A, Paula JS. Spatial correlation between localized decreases in exploratory visual search performance and areas of glaucomatous visual field loss. Graefes Arch Clin Exp Ophthalmol. 2019;257(1):153-160. https://doi.org/10.1007/s00417-018-4164-9

72. Cohen EH, Schnitzer BS, Gersch TM, Manish S, Kowler E. The relationship between spatial pooling and attention in saccadic and perceptual tasks. Vis Res. 2007;47(14):1907-1923. https://doi.org/10.1016/j.visres.2007.03.018

73. Marumoto T, Sotoyama M, Villanueva MBG, et al. Significant correlation between school myopia and postural parameters of students while studying. Int J Indust Ergon. 1999;23(1):33-39. https://doi.org/10.1016/S0169-8141(97)00098-X

74. Greene HH. Temporal relationships between eye fixations and manual reactions in visual search. Acta Psychol. 1999;101(1):105-123. https://doi.org/10.1016/ S0001-6918(98)00051-1

75. Kim YH, Yun C, Kim JT, Kim SW, Oh J, Huh K. The correlation between retinal sensitivity assessed by microperimetry and contrast sensitivity in diabetic macular oedema. Br J Ophthalmol. 2014:98(12):1618-1624. https://doi.org/10.1136/ bjophthalmol-2013-304765

76. Baraas RC, Gjelle JV, Finstad EB, Jacobsen SB, Gilson SJ. The relationship between perifoveal achromatic, L- and M-cone acuity and retinal structure as assessed with multimodal high resolution imaging. Vis Res. 2017:132:45-52. https://doi. org/10.1016/j.visres.2016.06.005

77. Skeel RL, Schutte C, Van Voorst W, Nagra A. The relationship between visual contrast sensitivity and neuropsychological performance in a healthy elderly sample. J Clin Exp Neuropsychol. 2006;28(5):696-705. https://doi.org/10.1080/ sample. J Clin Exp N3

78. Owsley C, Mcgwin, G, Sloane ME, Stalvey BT, Wells, Jennifer. Timed instrumental activities of daily living tasks: Relationship to visual function in older adults. Optom Vis Sci. 2001;78(5):350-359. https://doi.org/10.1097/00006324-20010 Optom Vis

79. Ueda T, Nawa Y, Masuda K, Ishibashi H, Hara Y, Uozato $\mathrm{H}$. Relationship between corneal aberrations and contrast sensitivity after hyperopic laser in situ keratomileusis. Jpn J Ophthalmol. 2006;50(2):147-152. https://doi.org/10.1007/ keratomileusis. Jpn

0. Tran TH, De Smet MD Bodaghi B, Fardeau C, Cassoux N Lehoang P. Uveitic macular oedema: Correlation between optical coherence tomography patterns with visual acuity and fluorescein angiography. Br J
2008;92(7):922-927. https://doi.org/10.1136/bjo.2007.136846

81. Smretschnig E, Falkner-Radler $\mathrm{Cl}$, Binder $\mathrm{S}$, et al. Vision-related quality of life and visual function after retinal detachment surgery. Retina. 2016;36(5):967-973. https://doi.org/10.1097/IAE.0000000000000817

82. Balaratnasingam $\mathrm{C}$, Inoue $\mathrm{M}$, Ahn $\mathrm{S}$, et al. Visual acuity is correlated with the area of the foveal avascular zone in diabetic retinopathy and retinal vein occlusion. Ophthalmology. 2016;123(11):2352-2367. https://doi.org/10.1016/j. ophtha.2016.07.008

83. Nolan JM, Stringham JM, Beatty S, Snodderly DM. Spatial profile of macula pigment and its relationship to foveal architecture. Invest Ophthalmol Vis Sci. 2008;49(5):2134-2142. https://doi.org/10.1167/iovs.07-0933

84. Arditi A, Cagenello R. On the statistical reliability of letter-chart visual acuity measurements. Invest Ophthalmol Vis Sci. 1993;34(1): 120-129.

85. Ranganathan $\mathrm{P}$, Pramesh CS, Buyse M. Common pitfalls in statistical analysis: Clinical versus statistical significance. Perspect Clin Res, 2015:6(3):169-170. https://doi.org/10.4103/2229-3485.159943

86. Page P. Beyond statistical significance: Clinical interpretation of rehabilitation research literature. Int J Sports Phys Ther. 2014;9(5):726-736.

87. Mariani AW, Pêgo-Fernandes PM. Statistical significance and clinical significance. Sao Paulo Med J. 2014;132(2):71-72. https://doi.org/10.1590/1516-3180.2014. 1322817

88. Houle TT, Stump DA. Statistical significance versus clinical significance. Semin Cardiothor Vasc Anesth. 2008;12(1):5-6. https://doi. org/10.1177/1089253208316440

89. LeFort SM. The statistical versus clinical significance debate. Image J Nurs Sch 1993;25(1):57-62. https://doi.org/10.1111/j.1547-5069.1993.tb00754.x

90. Ravikumar A, Sarver EJ, Applegate RA. Change in visual acuity is highly correlated with change in six image quality metrics independent of wavefront error and/or pupil diameter. J Vis. 2012;12(10):11. https://doi.org/10.1167/12.10.11 